\title{
The Research on Financing Predicament and Effectiveness of Small and Medium-size Enterprises in China
}

\author{
Xiuwei Tang \\ School of Economics and Management, Northeast Dianli University, Jilin, Jilin, China
}

\begin{abstract}
The primary purpose of the study is to explain the financing channels and effectiveness of Small and Medium-size Enterprises in China. China represents a good evaluation platform because it is one of the fastest growing emerging economies; China's economic growth depends on SMEs development. Lack of access to capital is the primary obstacle in developing vibrant SMEs in China. In order to solve the financing difficulty, commercial bank, venture capital and the local government has adopted various measures to support the development of SMEs. There are two main hypotheses posed by the study. The first one is there are pronounce liquidity gaps in the SMEs in China. The second is existing assistance programs are not effective in closing the liquidity gap in the SMEs in China.

Index Terms - small and medium-size enterprises, financing predicament, financing channel, financing effectiveness
\end{abstract}

\section{Introduction}

During economic reforms in China from 1978, the developing of small and medium-size enterprises (SMEs) has experienced rapid growth over the past more than three decades. SMEs are pivotal to success in economic development, as they played very important roles in fostering innovation and growth, with relevant economic impacts on job creation, increased industry competitiveness, and the generation of long-term skills and know-how.

However limited by their own characteristics, one of the largest difficulties of developing SMEs is lacking of capital. These situations may arise for a variety of reasons, including supply-side challenges, intermediation challenges and demand-side problems (Mason and Kwok, 2010; North et al., 2010; Oakey, 2007; Mason and Harrison, 2004b). In terms of supply of capital, capital limitations may come from actual shortages in the marketplace where private sector participants effectively "hoard" capital and are unwilling to extent it to SMEs. A gap may also result from intermediation challenges where firms are unable to connect to the "right" capital providers; this can result from asymmetric information or the moral hazards faced by capital providers (Hughes, 2009; Bruns and Fletcher, 2008). In terms of demand-side challenges, SMEs are vulnerable, and very few manage to survive more than five years; SMEs may not actually warrant financing (North et al., 2010; Hughes, 2009); Firms may not meet the financing criteria set by capital providers related to profitability, liquidity, and growth potential. In general terms, lenders seek businesses that are profitable and have suitable collateral, while equity providers look for profitable ventures with high growth potential. Some SMEs may also not be investment-ready (Mason and Kwok, 2010; Hughes, 2009; Oakey, 2007; Mason and Harrison, 2004a); reasons for this include a lack of business plan and an incomplete management team. Other problems that arise may relate to the SMEs' past debt management, suboptimal collateral, or excessive taxation (North et al., 2010; Hughes, 2009).

The problem of access to capital becomes even more challenging in China's capital market for a variety of reasons (Benedict and Venter, 2010; Cunningham and Rowley, 2010; Le and Nguyan, 2009; Klonowski, 2005; Abor and Biekpe, 2006; Tagoe et al., 2005). First, firms in China operate in an environment of imperfect legal infrastructure (Cunningham and Rowley, 2010; Klonowski, 2005). Second, financial disclosure in China's capital market continues to be relatively poor (see, for example, Sami and Zhou, 2008; Zhou, 2007; Klonowski, 2009). The firms in this market report financial results under their own financial standards and regulations, which are different from those seen in international accounting standards; consequently auditing firms must often recast the financial statements of firms operating in this market. Third, asymmetry of information and moral hazards are more pronounced in China (See, for example, Le and Nguyan, 2009; Klonowski, 2007; Tagoe et al., 2005). Access to information is a greater challenge, as sources of information on firms, the competitive posture of market players, and market size and growth rates are more difficult to find (see, for example, Abor and Biekpe, 2006; Tagoe et al., 2005). Fourth, firms operating have more problems related to corporate governance. The corporate governance concerns are more severe and more difficult to address than those experienced by firms in developed economies (see, for example, Black et al., 2010; Klonowski and Golebiowska-Tataj, 2009; Parisi et al., 2009). Key issues may include the personal use of a firm's assets, unaccounted cash withdrawals, and appointment of family members.

\section{The Financing Channels of SMEs}

SMEs can generate capital either internally or externally which defined according to the fact whether one finance arrangement will dilute or transfer entrepreneur's control right. The internal finance include the fund of enterpriser and her/his family, profit retain, employee hold share and enterpriser social relation network finance. But most of the SMEs are start-up firms, the beginner enterprises are often "virtual"; there is only an idea, concept, or invention driving the ultimate development of a full business, most of them are not profitable, their own resources are limited.

External capital to the SMEs can come from three basic sources: banks, venture capital, and the government. Commercial banks traditionally represent the most important source of SME financing and can satisfy up to 80 percent of 
SME capital needs (Bruns and Fletcher, 2008). However, obtaining external finance from a bank can be challenging for firms operating within the SMEs. Banks do not tolerate risk well, and risks are inherent in the SMEs. Banks may also not be "friendly" to business owners, particularly the owners of new firms who want to expand their products, build new facilities, or develop markets outside of their home territory (Bruns and Fletcher, 2008). In addition banks require collateral that can exceed the value of the initial loan by two to three times. If firms from the SMEs experience financial or operational troubles, banks may cease their assistance or, at best, refer the troubled case to a workout department.

Bank financing alone may not be sufficient to finance the innovation or growth of SMEs (Bruns and Fletcher, 2008; Avnimelech and Teubal, 2008). Additional financing can come from venture capital, by which we mean the professional asset management activity that invests funds raised from institutional investors, or wealthy individuals, into promising new ventures with a high growth potential (Marco Da Rina, Thomas Hellmannb, and Manju Puric, 2011). Venture capital traditionally provides financing to less than 10 percent of SMEs that require finance (Oakey, 2007). However, there are also challenges inherent in this type of financing. First, venture capitalists are highly selective in their choice of investee firms. Traditionally venture capitalists provide financing to one out of every one hundred business plans they review; many firms are simply not suitable for this type of financing. Second, venture capitalists may place significant impositions on a business owner. Venture capitalists focus on exit, which aims to provide them with an opportunity to cash out of their illiquid investment; this forces the investee firm to be sold to strategic investors or list its shares on the public market at the end of the holding period. Venture capitalists may also take an active role in approving key operational, strategic, and financial decisions, which can be disruptive to business owners who value their independence. Third, venture capital financing is relatively expensive in comparison to other forms of financing.

Because of the financing gap of SMEs and the market failure, it is important for the government to support the private SMEs' financing. Since the mid-1980s the Chinese government has established programs aimed at easing access to finance for the SMEs, which offer financial assistance (loan or grants). There are four trends in establishing policies for SMEs' development. First, set policy of legislation protection for SMEs, creates favorable environment for SMEs, and overcomes all kinds of disadvantage. Second, set policy of industry support, supporting high-tech industry to achieve the transformation of Chinese economy from quantity expanding mode to quality benefit mode. Third, set policy of technical creation, government supporting programs especially address a wide spectrum of solutions related to technical creation, including choosing technical creation as priority in supporting SMEs; Encouraging creation by economic methods; building up relative laws to protect creation and boosting creation mainly by product creation. Forth, set policy of favored finance, serve credit support by a specific institution of government, build credit guaranteeing system, build the discount system and other financial supporting system; set policy of social service system, including information service, human resource service and agency service.

\section{Effectiveness of Financial Support Programs}

The finance problem presented before SMEs has not yet been solved effectively although relevant department have taken measures to promote finance for them.

First, this problem is because of the traditional financial management system of "catching up and surpass" strategy. This "catching up and surpass" strategy insist on investing preferentially on capital-intensive heavy firms with large investment scale, long construction circle and important equipment. Government established strict financial market access standards, restricting foreigners from entering, which gradually resulted in highly monopolized at the financial market by national banks. With the financially suppressed system design, the banks continue restrict SMEs from entering the market, favor large-scale state-owned enterprises in the form of credit rationing, therefor it is not surprising that this will eventually bring about finance difficulties in SME sector.

Second, venture capital market in China is in its infancy, and the country's immature equity market fails to offer the dependable exit route demanded by sophisticated early-stage investors. VC investing that highlights a refinancing inefficiency that arises from the fixed maturity of venture fund. Good projects that require more time to become profitable may be terminated because the opportunity cost of the VCs' monitoring capital is too high. And bad projects may be refinanced if the market is unable to distinguish them from good ones that have yet to mature.

Second, the effectiveness of SMEs support programs developed and delivered by the Chinese government and its dependent agencies and organizations. Chinese government assistance programs are fragmented and based on a multilayered approval and decision-making system. These programs may be inefficient and duplicate efforts, and they may be very broad and dedicated to a wide variety of audiences. The application process is cumbersome. Applicants needed to develop a comprehensive package, including their application, numerous documents, certificates, confirmations, and financial statements. The government programs were more demanding of information and written material than banks were when granting loans. The programs did not reflect SMEs' actual needs. Most SMEs indicated that their firms have developed relatively quickly in terms of sales and have outgrown the programs offered by the government. They suggested that the programs need to be tailored to stages of business development rather than focused on government-preferred themes. The firms also complained about the lack of highly specialized advisors in key business areas. The government programs are not well tuned to their firms' business environment and actual needs. SMEs indicated that the external advisors preferred to be involved in discrete tasks rather than in overall business development. Many government assistance programs do not appear to meet the 
actual needs of the SMEs. The usage of these programs was found to be poor. Other concerns related to copayment or co-investment requirements, the limited availability of exhaustive paper or Internet-based information on the programs, and the fragmented nature of many programs, for instance, too many programs made it difficult to find an available, appropriate program that fit a firm's needs.

\section{Conclusion}

Enterprises, bank, venture capitals, and government assistance programs play different roles in the financing of SMEs. Problems can be solved only on basis of rationalization caused from effectiveness. In the financing system of SMEs, a virtuous relationship of interaction shall be established among enterprises, bank and government department oriented to their own roles, by which only can problems be solved, in particular, in the early stage of enterprises' growth. In the financing, these participants together establish a policy-permitted commercial financing system for SMEs. Especially, government departments should to engage in creating sound exterior environment for the financing of enterprise and making arrangement for the enterprises in the early stage.

\section{References}

[1] Abor, Joshua, and Nicholas Biekpe. 2006. "SMEs access to debt finance: A comparison of male-owned and female-owned business in Ghana." International Journal of Entrepreneurship and Innovation Management 7:2, 105-112.

[2] Atherton, Andrew, and Alaric Fairbanks. 2006. "Stimulating private sector development in China: The emergence of enterprise development centers in Liaoning and Sichuan provinces." Asia Pacific Business Review 12:3, 333-354.

[3] Avnimelech, Gil, and Morris Teubal. 2008. "From direct support of business sector $\mathrm{R} \& \mathrm{D}$ innovation to targeting venture capital/ private equity: A catching-up innovation and technology policy life cycle perspective." Economics of Innovation and New Technology 17:1-2, 153-172.

[4] Benedict, Ekaele, and Percy Venter. 2010. "Education, entrepreneurial mindset and innovation: Necessary ingredients for increasing entrepreneurial activity in South Africa." International Journal of Entrepreneurship and Innovation Management 11:2, 239-253.

[5] Black, Bernard, Antonio de Carvalho, and Erica Gorga. 2010. "Corporate governance in Brazil.” Emerging Markets Review 11:1, 21-38.

[6] Bruns, Volcker, and Margaret Fletcher. 2008. "Banks' risk assessment of Swedish SMEs." Venture Capital: An International Journal of Entrepreneurial Finance 10:2, 171-194.

[7] Cunningham, Li, and Chris Rowley. 2010. "Small and medium-sized enterprises in China: A literature review, human resource management, and suggestions for further research." Asian Pacific Business Review 16:3, 319-337.

[8] Dagogo, Daibi, and Walter Ollor. 2009. "The effect of venture capital financing on the economic value added profile of Nigerian SMEs." African Journal of Accounting Economics, Finance, and Banking Research 5:5, 37-46.

[9] Di Giacomo, Marina. 2004. "Public support to entrepreneurial firms." Journal of Private Equity 8:1, 22-38.

[10]Guijarro, Antonia, Domingo Garcia, and Howard Van Auken. 2009. "Barriers to innovation among Spanish manufacturing SMEs." Journal of Small Business Management 47:6, 465-488.

[11]Hughes, Alan. 2009, "Hunting the snark: Some reflections on the U.K. experience of support for the small business sector." Innovation: Management, Policy and Practice 11, 114-126.

[12]Karsai, Judit. 2004. "Can the state replace private capital investors?" Discussion Paper, Institute of Economics, Hungarian Academy of Sciences, Budapest.

[13]Klonowski, Darek. 2005. "The evolution of the venture capital industry in transition economies: The case of Poland." Post-Communist Economies $17: 3,331-348$.

[14]Klonowski, Darek, and Daria Golebiowska-Tataj. 2009. "When East meets West: Corporate governance challenges in emerging markets of Central and Eastern EUROPE-The case of Polish Aggregate Processors. " Post-Communist Economies 21:3, 361-371.

[15]Mason, Colin, and Richard Harrison. 2004a. "Business angel networks and the development of informal venture capital market in the U.K.: Is there still a role for public policy?" Small Business Economics 9:111-123.

[16]Mason, Colin, and Richard Harrison. 2004b. "Improving access to early stage venture capital in regional economies: A new approach to investment readiness." Local Economy 19:2, 159-173.

[17]Zhou, Haiyan. 2007. "Auditing standards, increased accounting disclosure, and information asymmetry: Evidence from an emerging market." Journal of Accounting and Public Policy 26:5, 584-620. 